\title{
Discussion on the innovation of enterprise investment management
}

\author{
Pengwu Wang ${ }^{1, \text { a }}$ \\ ${ }^{1}$ School of Accounting, Harbin University of Commerce, Harbin City, Heilongjiang Province, China, \\ 150028 \\ a email:
}

Keywords: Enterprise Investment, Financial Management, Deviation, Innovation

\begin{abstract}
With the gradual increase of social competition, the enterprise's financial investment management has become an important way to obtain economic benefits and achieve sustainable development. Based on the author's work practice, this paper first analyzes the enterprise investment decision makers' cognitive bias and irrational behavior, and then, it puts forward the financial innovation strategies of the enterprise investment decision: The enterprise investment decision maker must be familiar with the characteristics of various cognitive biases and irrational behaviors in the investment decision, be good at learning, understanding and accepting new investment idea of behavior finance, keep calm, self-discipline mentality, implement collective decision-making and scientific decision-making, establish an investment project termination mechanism.
\end{abstract}

\section{The Interpretation of Enterprise Investment Management}

Corporate investment activities are also defined as the capital allocation behavior of enterprises, including investment related to the owners, diversified operations, mergers and acquisitions, etc. According to the direction of investment, enterprise investment is divided into internal investment and foreign investment. From the enterprise point of view, the internal investment is the project investment, which means an investment used in the fixed assets, intangible assets and other assets. Foreign investment means the investment in a company's capital injection in order to purchase securities or other financial products issued by the the state and other enterprises. From the behavioral financial theory, enterprise investment is a kind of conscious economic behavior, and the investment behavior is regulated by the investor's psychological consciousness. In fact, investment decision-making motivation, investment income expectations, investment risk preferences and other issues are people's psychological activities in the specific performance of the investment. Corporate investment behavior is an investment decision based on the advantage of motivation after being stimulated by the information and current events, through a series of psychological activities and behavior process.

\section{The Cognitive Bias and Irrational Behavior of Enterprise Investment Decision Maker}

Overconfidence. Psychological experiments and studies show that: People tends to be too confident to judge their own ability, overestimate the probability of their own success and success is due to their ability, underestimating the role of luck, opportunity, and external forces, this cognitive bias is called "over confidence". Over confidence is a typical and widespread psychological bias, and it plays an important role in the investment decision-making process. Overconfident decision 
makers always has the arbitrariness of his decision, using their own wills to replace the law of the development of objective things. When the objective environment changes, they are not willing to change their own goals and plans, refuse to other people's opinions or suggestions, which is the lack of awareness of the performance.

A large number of studies show that investors are over confident of their ability to invest, which is mainly performed in two aspects: First, the prediction of over confidence, that is, when the investment forecast, the investor confidence interval is too narrow; Second, the certainty of over confidence, that is, people often have excessive confidence in their ability to judge.

Confirmation Bias. Confirmation bias means once people form a strong belief or make investment decisions, they will be consciously looking for evidence to prove their beliefs or investment decisions, no longer focus on the evidence that denies the idea or investment decisions, and artificially distort the new information. Enterprise manager's confirmation bias are more performed in the follow aspects: For the item that is not feasible for belief, they tend to seek positive information and refuse to give up the implementation of the project, resulting in the decision-making mistakes, even the same mistake again.

Loss Aversion. The loss amount giving up an item is more than the equivalent of an item, and this phenomenon is called loss aversion. One of the most important discoveries of Tversky and Kahneman's prospect theory is the asymmetry of people's decisions in the face of gains and losses; The impact of a loss on people is about 2.5 times as much as that of the same income. There are several kinds of behavior deviation related to loss aversion: First, the endowment effect. Because the pain people give up what he has is bigger than the joy getting an original does not belong to his goods, in terms of pricing, selling the same goods in this case is much higher than the purchase price. Knetsch calls this kind of phenomenon as endowment effect, that is, for the same thing, if we already have, then the price will be high; If we do not have it, then we are willing to pay a relatively high price. Second, maintaining the quo bias status. If there is a loss, people will not be willing to exchange the goods they already have, but are more willing to settle, even with the loss and gain. This is because the loss is more difficult to bear than the profit, so people prefer to maintain the status quo.

Frame Deviation. People's perception and judgment of things has a dependency on the background, then, the surface form of things will affect people's view of the nature of things. When it is used to describe the decision making problem, the form of things is often referred to as the frame. When a person sees a problem through a frame which is not transparent, his judgment and decision will depend largely on the specific frame set by the problem, and this is called Framing Depen-dence. The deviation of cognition and judgment caused by the frame dependence is called Framing Bias, which means the people's judgment and decision depend on the form of the decision problem. Although the nature of the problem is the same, it will lead to people make different decisions because of the different expression form.

\section{Behavior Financial Innovation Strategies in Enterprise Investment}

Enterprise investment decision makers must be familiar with the characteristics of various cognitive bias and irrational behavior in the enterprise investment decision-making to reduce and prevent the loss caused by their investment to the enterprise. In this paper, the characteristics of various cognitive biases and irrational behaviors in the process of investment decision are discussed. For example, in investment, on the one hand, to minimize and control the occurrence of cognitive bias and irrational financial behavior; On the other hand, in the cognitive bias and irrational financial behavior, it can be realized immediately and take certain measures to control and reduce 
the losses caused by the enterprise investment.

Business investment decision makers must be good at learning, understanding and accepting new ideas of financial related behavior. Behavioral finance has put forward a new idea of finance, and these financial ideas have good explanatory power and guidance for the development of the financial management practice, at the same time, it also helps to correct the cognitive bias and irrational financial behavior of enterprise investment decision makers. Enterprise investment decision makers should learn and accept these new financial ideas. These new ideas include: Finance man is limited rational; The financial person is in accordance with the rules of thumb to make decisions, not to make decisions based on the law of Bayesian statistics; The financial person is in accordance with the principle of satisfaction to make decisions, rather than in accordance with the principle of maximizing the effectiveness and the optimal decision-making; The preference of the financial person is not stable, the decision-making objectives include the value of psychological factors, and the theoretical model is more in line with prospect theory rather than the expectation theory of utility maximization; The financial person is the actor, so the financial person's sentiment has the serious influence on the capital market's asset price; Arbitrage is limited, and the market is not effective. The financial person mentioned above includes both the decision maker from the enterprise internal investment and the vast number of investors and market analysts from outside the enterprise. Enterprise investment decision maker should remain modest, calm, self-discipline mentality to achieve collective decision-making and scientific decision-making in different forms of business. Investment decisions to solve the problem, not only to consider the objectives of the enterprise as well as the related strategic issues, but also to consider a range of tactical issues, to deal with various relationships, contradictions.

Therefore, in order to avoid the mistakes of business investment, especially in the major investment projects or in the field of investment that is not familiar with, it is necessary to truly implement collective decision-making and democratic scientific decision-making, to prevent a personal decision-making heuristic bias, loss aversion and other cognitive biases.

An effective corporate governance mechanism, can greatly reduce the mistakes in investment decisions made by the cognitive bias and irrational behavior of enterprise investment decision makers. In the partnership enterprise, it needs to ensure the investment decisions of enterprises are made by the partner after a democratic consultation. In a sole proprietorship enterprise, business owners are required to be good at listening to the opinions of professional managers or professional organizations or even employees, and on this basis, it can realize the collective decision-making and scientific decision-making. In terms of number and form, the partnership enterprise is more difficult than the collective in the decision making and democratic decision making of the investment. How to prevent over self confidence? This may find the answer from the Chinese traditional culture. The investment decision maker of the enterprises should be a modest and prudent person, and build the relevant corporate culture, create a liberal and harmonious atmosphere of democratic innovation in enterprise.

From the technical aspects, it should establish a mechanism for the termination of investment projects; In the investment decision-making evaluation of major investment projects, it needs to ask the enterprise external professional project evaluation and decision-making advisory body to carry on the demonstration consultation; Set up investment appraisal project team and project team in the enterprise to effectively correct the cognitive deviation. Establish the termination mechanism of investment projects. When an investment project is in a loss and can't turn a profit in a predictable period, rules should be made to help the decision makers to overcome poor self-control. For example, companies can develop hard rules, when the original investment of an investment project 
is required to take up the capital required by the normal business operations of the enterprise and it may have an impact on the cash flow of the enterprise, it needs to immediately terminate the project. It can be also specified if the loss of investment projects reached $20 \%$ of the total amount of the original investment in the operating period or achieved the maximum limit of the enterprise, the investment of the project and the operation of the project should be terminated, which can lock the investment losses to prevent further expansion of investment losses, so the mechanism can help enterprises to correct the investment decision maker's "confirmation bias".

\section{Conclusion}

With the increase and improvement of China's investment intermediary institutions, in enterprise major investment projects, it needs to ask the enterprise external professional project evaluation and decision-making advisory body to carry on the demonstration consultation, issue the demonstration consultation report; Setting up an investment project team or project team in the enterprise, listen carefully to all aspects of the views of the staff to make investment decision-making more scientific and more perfect; By means of these methods, it is helpful to correct the cognitive bias, such as "loss aversion and frame bias" of investment decision makers.

\section{References}

[1] Tong Hu. Research on the financial management of science and technology small and medium sized enterprises [D]. Tianjin University of Technology, 2002.

[2] Yang Xueyan. Study on financial management of small and medium sized enterprises of science and technology [D]. Tianjin University of Technology, 2002

[3] Zhao Kexue. Institutional innovation of venture capital industry in China [D]. Tianjin University, 2007

[4] Zhou Qian. Research on the investment of the mobile communication enterprise [D]. Beijing University of Posts and Telecommunications, 2006

[5] Zhu Li. The innovation of enterprise financial investment management strategy in the new period [J]. modern economic information, 2016,04:275. 